\title{
POR UMA POLÍCIA MODERNA E RESPEITÁVEL: POLÍCIA E POLICIAIS EM PORTO ALEGRE (1886-1928)
}

\author{
For a modern and decent police: police and \\ policeman in Porto Alegre (1886-1928)
}

\author{
Cláudia Mauch ${ }^{*}$
}

\begin{abstract}
RESUMO
O artigo analisa a polícia de Porto Alegre, capital do Rio Grande do Sul, ao longo da Primeira República, particularmente por meio do sistema de recrutamento e dos motivos das demissões, que evidenciam a aplicação de critérios clientelistas de seleção e as dificuldades de disciplinarização e estabilização dos efetivos policiais. A pesquisa se baseia principalmente em fontes seriadas, como registros de pessoal, e qualitativas, como inquéritos administrativos abertos para investigar desvios de conduta de policiais. Os casos individuais descritos nos inquéritos iluminam práticas provavelmente corriqueiras e regras informais, ajudando a evitar a despersonalização da instituição. Tomadas em conjunto, as fontes permitem um melhor entendimento do funcionamento da polícia local, para além das idealizações expressas nos regulamentos. Permitem, enfim, analisar a inter-relação entre duas dimensões: o que o Estado espera da polícia e como a instituição policial se modela nas suas relações internas.
\end{abstract}

Palavras-chave: polícia; recrutamento; disciplina

\begin{abstract}
The article analyzes the Porto Alegre city police, in the brazilian South, during the period known as First Republic (1889-1930), particularly through the recruitment system and the reasons for

* Doutora em História pela UFRGS. Departamento de História, Universidade Federal do Rio Grande do Sul. E-mail para contato: claudia.mauch@ufrgs.br
\end{abstract}


the dismissals and high turnover, which show the enforcement of clientelistic selection criteria and the difficulties in disciplining the police force. The empirical research is based on serial sources such as personnel records, and qualitative ones, as inquiries that had been opened to investigate policeman misconduct. The individual cases described in the qualitative sources enlighten informal policing practices and rules, helping to avoid the depersonalization of this institution. Taken together, these sources allow a better understanding about the shapping of the local police, going further from the idealizations expressed on the rules. They allow, finally, to explore the interactions between two dimensions: what does the state expect from the police force and how the police institution had been shaped in its internal relations.

Keywords: police; recruitment; discipline

A historiografia sobre as décadas iniciais do século XX no Brasil tem demonstrado a importância que instituições incumbidas de um papel civilizador e moralizador adquiriram na nova ordem republicana. ${ }^{1}$ As noções de desordem e crime se alargaram, passando a incluir novos sujeitos e comportamentos, de modo que ao medo dos escravos e suas revoltas, bandos armados e forasteiros, somou-se o dos pobres com comportamento "desregrado", pessoas de "costumes viciosos", "menores" delinquentes, anarquistas e, dependendo do contexto local, imigrantes. As polícias, como outras agências de controle social criadas ao longo desse período, tiveram seus poderes ampliados com a finalidade de lidar com essa gama de novos e reeditados medos, dentro de uma situação de participação política restrita e profunda desigualdade social. ${ }^{2}$

Baseados nas experiências consideradas positivas de outros países, notadamente Inglaterra e França, e nos avanços da

1 BRETAS, Marcos Luis; ROSEMBERG, André. A História da Polícia no Brasil: balanço e perspectivas. Topoi. Revista de História, Rio de Janeiro, v. 14, n. 26, p. 162-173, jan./jun. 2013. p. $165-166$.

2 SOUZA, Luís Antonio Francisco de. Lei, cotidiano e cidade: polícia civil e práticas policiais na São Paulo republicana (1889-1930). São Paulo: IBCCRIM, 2009. p. 24-25. BRETAS, Marcos Luiz. Ordem na cidade: o exercício cotidiano da autoridade policial no Rio de Janeiro: 1907-1930. Rio de Janeiro: Rocco, 1997. 
criminologia, então ciência da moda, ${ }^{3}$ elites e governantes da recém instaurada República brasileira viam a polícia como um dos instrumentos centrais para lidar com os sinais do atraso que atravancavam o caminho para alcançar o "adiantado grau de civilização" que o país almejava. A "modernização" da polícia, por si só, era considerada índice de civilização.

Como outras "novas polícias", a instituída para a capital do Rio Grande do Sul em finais do século XIX pretendia ser formada por homens "respeitáveis". Nos textos dos regulamentos, relatórios oficiais e opiniões da imprensa local os "bons policiais" eram idealizados como honestos, educados, cordiais, com elevada moral e disciplina, o que os diferenciaria dos agentes das forças policiais anteriormente existentes, que chegaram a ser definidos como "soldados boçais, recrutados na vasa dos botequins ou à porta das cadeias". ${ }^{4}$ Mas transformar homens do povo em policiais exigia mais do que boas intenções. Para além de constatar o distanciamento entre os projetos expressos nas leis e regulamentos e as experiências práticas das instituições, torna-se necessário entender como as polícias brasileiras funcionavam, considerando a diversidade de modelos adotados pelos governantes nos estados na Primeira República. Nesse sentido, este artigo analisa a polícia de Porto Alegre ao longo desse período, particularmente por meio do sistema de recrutamento e das formas de desligamento então empregadas, que evidenciam a aplicação de critérios clientelistas de seleção e as dificuldades de disciplinarização dos policiais. A pesquisa se baseia principalmente em fontes seriadas, como registros de pessoal, e qualitativas, como inquéritos administrativos abertos para investigar desvios de conduta de policiais. Os casos individuais sobre os quais foram obtidas mais informações iluminam relações e práticas provavelmente corriqueiras e ajudam a evitar a despersonalização e uniformização das instituições que, como a polícia, são disciplinadoras e disciplinares. Com esse estudo, pretende-se

3 ALVAREZ, Marcos César. A criminologia no Brasil ou como tratar desigualmente os desiguais. Dados. Rio de Janeiro, v. 45, n. 4, p. 677-704, 2002.

4 Opinião expressa pelo deputado e advogado Germano Hasslocher no seu jornal Gazeta da Tarde na época da criação da Polícia Administrativa de Porto Alegre. Gazeta da Tarde. Porto Alegre, 1 dez. 1896. Museu da Comunicação Social Hipólito José da Costa. 
contribuir para o conhecimento das experiências organizacionais de polícia no início da República brasileira, num período onde tanto a profissionalização da atividade era precária, quanto os governos estavam abertos a diferentes modelos de modernização do policiamento. Mesmo que similares em seus objetivos mais gerais expressos em leis e regulamentos, as polícias locais apresentam muitas particularidades quando analisamos suas tarefas práticas, sua composição e relações de poder internas e externas. As noções de como o "bom policial" devia ser e como devia executar suas tarefas até mesmo quais eram essas tarefas - foram se transformando na interrelação entre as prescrições oficiais e as práticas concretas dos policiais nas ruas e dentro da corporação.

No final do século XIX os governantes republicanos do Rio Grande do Sul, após terem derrotado em campo de batalha seus oponentes na Revolução Federalista, trataram da reorganização institucional e administrativa do estado. Uma das instituições reformadas foi a polícia, que passou a ser constituída por uma organização civil estadual cuja tarefa era a investigação criminal, a Polícia Judiciária, e polícias municipais administrativas civis e uniformizadas responsáveis pelas tarefas de policiamento. No caso de Porto Alegre, a Polícia Administrativa tinha funções amplas: além do policiamento diurno e noturno das ruas, da captura de criminosos e execução de mandados de autoridades judiciais, de "evitar as rixas e compor as partes", por em custódia os turbulentos e desordeiros, era também responsável por extinguir incêndios, cuidar da tranquilidade e circulação das vias públicas e outros serviços

O primeiro regulamento da Polícia Administrativa de Porto Alegre estipulava que o ingresso se daria por voluntariado, o que já era uma diferença importante em relação às polícias provinciais, cujo recrutamento era compulsório. Os candidatos deveriam ter idade mínima de 21 anos, "saber ler e escrever e ter inteligência e aptidão necessárias para o serviço", além de apresentar atestado de moralidade e boa conduta fornecido por "cidadão idôneo". No texto, publicado em 1896, não havia qualquer menção a condições físicas, como estatura ou peso, ou preferência por habilidades profissionais anteriores, como ocorria em polícias de outros países.

A Polícia Metropolitana de Londres, desde sua criação em 1829, visava recrutar homens jovens e respeitáveis das classes 
trabalhadoras com no mínimo 1,75 metros de altura, até 35 anos, alfabetizados e "abençoados com perfeito domínio do temperamento". ${ }^{5} \mathrm{Na}$ segunda metade do século XIX a Polícia Civil de Lisboa, cujas tarefas prescritas em regulamento em muito se assemelhavam às da Polícia Administrativa de Porto Alegre, exigia que os candidatos tivessem servido em algum corpo do exército, apresentassem "suficiente robustez e boa aparência", não tivessem altura inferior a 1,60 metros e fossem alfabetizados. ${ }^{6}$ No início dos anos 1930, a polícia londrina, cujo modelo organizacional inspirava governantes mundo afora ${ }^{7}$ e que nessa época já oferecia aos ingressantes a perspectiva de uma carreira, exigia, além de outras habilidades, homens altos, em perfeitas condições de saúde e aplicava aos candidatos um exame escrito que eliminava cerca de dez por cento dos pretendentes. ${ }^{8}$

No Brasil, as pesquisas sobre o perfil social dos policiais que atuavam nas ruas são escassas, em grande medida porque a historiografia raramente os encara como trabalhadores com alguma possibilidade de agência. No Rio Grande do Sul, os trabalhos de Paulo Moreira e Caiuá Al-Alam sobre a composição das forças policiais no século XIX representam exceção a essa tendência. ${ }^{9}$ Para as últimas décadas do período imperial, André Rosemberg pesquisou a composição das polícias da província de São Paulo, sendo a

5 EMSLEY, Clive. The English Police: a political and social history. 2. ed. London, New York: Longmann, 1996. p. 191.

6 VAZ, Maria João. Vigiar a cidade: a Polícia Civil de Lisboa (1867-1910). In: PINA, Ana Maria, MAURÍCIO, Carlos, VAZ, Maria João (orgs.). Metamorfoses da cultura: estudos em homenagem a Maria Carlos Radich. Lisboa: Centro de Estudos de História Contemporânea, ISCTE, Instituto Universitário de Lisboa, 2013. p. 317-356.

7 ROSEMBERG, André. Polícia, policiamento e o policial na Província de São Paulo, no final do Império: a instituição, prática cotidiana e cultura. Tese de doutorado. PPG em História Social, Universidade de São Paulo. São Paulo, 2008. p. 37.

8 WEINBERGER, Barbara. The best police in the world: an oral history of english policing from the 1930s to the 1960s. Aldershot: Scholar Press, 1995.

9 MOREIRA, Paulo Roberto Staudt. E a rua não é do Rei. Morcegos e populares no início do policiamento urbano em Porto Alegre, século XIX. In: HAGEN, Acácia Maria Maduro, MOREIRA, Paulo Roberto S. (orgs.). Sobre a rua e outros lugares: reinventando Porto Alegre. Porto Alegre: Caixa Econômica Federal, 1995. p. 51-96. AL-ALAM, Caiuá Cardoso. A negra forca da princesa: polícia, pena de morte e correção em Pelotas (1830-1857). Dissertação de mestrado. São Leopoldo: UNISINOS, 2007. Acrescento aqui meu próprio trabalho: MAUCH, Cláudia. Dizendo-se autoridade: policia e policiais em Porto Alegre (1896-1929). Tese de doutorado. Porto Alegre: PPG em História UFRGS, 2011. 
Companhia de Urbanos criada em 1875 a força desmilitarizada encarregada do policiamento preventivo na capital. Os guardas dessa "nova polícia" deveriam ser alfabetizados, amáveis, prudentes, polidos e corteses. ${ }^{10}$

Em Porto Alegre, o regulamento da polícia local sofreu algumas modificações em 1914, dentre elas a especificação de que os lugares de inspetores seriam preenchidos "por acesso, observando-se em regra a antiguidade e, excepcionalmente, o mérito". Mas também foi incluída a necessidade de prestação de concurso para o cargo de amanuense e para acesso à categoria de inspetor efetivo, o que eliminava a possibilidade de analfabetos exercerem esses cargos. Em princípio, até 1914 a possibilidade de ascensão dentro da Polícia Administrativa estava aberta a todos os que entravam. A instituição não tinha muitos níveis hierárquicos: inicialmente eram dois (vigilantes e comissários), que em seguida mudaram a denominação e passaram a três (agentes, inspetores, auxiliares), depois a quatro (mais auxiliar-chefe). Agentes e inspetores faziam o policiamento de rua ordinário e os serviços especiais ${ }^{11}$, enquanto os demais eram auxiliares imediatos do subintendente do distrito e ficavam de plantão nos postos policiais. Para os cargos de auxiliares, seriam preferidos os inspetores que mais se houvessem distinguido por "inteligência e moralidade". A ascensão para acima do cargo de inspetor era mais restrita, pois eram poucos os cargos de auxiliar e auxiliar-chefe. O cargo de comando mais alto em cada distrito, o de subintendente, era de nomeação política do intendente municipal, e não parece ter sido ocupado por algum ex-agente, inspetor ou auxiliar. ${ }^{12}$

10 ROSEMBERG, op. cit. p. 46 a 49.

11 Eram considerados serviços especiais: 1) serviço de veículos; 2) vigilância de teatros, hipódromos, festas e outros espetáculos públicos; 3) captura de criminosos por requisição das autoridades judiciárias; 4) guarda e segurança dos edifícios públicos municipais; 5) outros serviços previstos nos artigos $6^{\circ}$. e $8^{\circ}$. da lei de reorganização policial do Rio Grande do Sul de 1896 (artigos que deixavam ao município a autonomia para definir o funcionamento e detalhar as funções das polícias administrativas).

12 Essa conclusão baseia-se no cruzamento dos nomes de subintendentes levantados na pesquisa com nomes presentes nos registros de pessoal. Além das funções policiais, que eram então bastante amplas, os subintendentes eram administradores distritais. No caso dos quatro principais distritos urbanos de Porto Alegre, verificou-se em alguns períodos o acúmulo de funções de polícia administrativa e judiciária, com os subintendentes atuando como delegados judiciários. 
É difícil saber quem e como decidia sobre a "inteligência e aptidão" dos candidatos, ou seja, como se efetivava o recrutamento. Dados obtidos nos códices de Matrícula de Pessoal ${ }^{13}$ dos ingressantes indicam que a posse do atestado de conduta era o mais necessário dos requisitos. Os outros dois, ser maior de 21 anos e alfabetizado, nem sempre eram seguidos: 161 homens tinham menos de 21 anos quando ingressaram na polícia. A alfabetização não consta como campo da Matrícula e, por isso, não pode ser quantificada. Informações indiretas de outros documentos e ocasionalmente do campo "observações" do registro de pessoal fornecem pistas sobre o grau de alfabetização da polícia municipal no início do século XX. Em 1905 o policial Ursino - que havia ingressado em 1899 com 20 anos de idade - foi promovido a inspetor graduado com a seguinte justificativa: "preterindo outros mais antigos por ser o único que sabe ler e escrever". ${ }^{14}$ Esse foi um dos poucos policiais que ficou mais de 25 anos na corporação, e pode-se especular se ser alfabetizado tenha contribuído para sua permanência na profissão.

Possivelmente saber ler e escrever fosse o critério mais difícil de preencher, e acredito que não era sistematicamente aferido pelos recrutadores, que poderiam também considerar alfabetizado aquele que conseguisse apenas desenhar o nome, como o ex-praça piauiense Agostinho, que assinou o nome com letra vacilante (iniciou duas vezes) abaixo do parecer sobre sua expulsão. $\mathrm{Ou}$, mais explicitamente, o ex-pintor baiano Manoel que "entrou para a Polícia enganando que sabia ler e escrever sendo mentira". ${ }^{15} \mathrm{Na}$ prática, o serviço comum de patrulhamento das ruas podia ser executado por analfabetos, pois somente dos inspetores, auxiliares e dos próprios

13 Foram consultados 22 códices de documentação de pessoal dos distritos e postos policiais urbanos e suburbanos de Porto Alegre cujos registros cobrem o período 1896 a 1928 , denominados "Matrícula Geral do Pessoal da Polícia Administrativa do [...] Posto". A fonte contém dados pessoais dos policiais no momento em que entravam na corporação e informações sobre licenças, punições, promoções e desligamentos. Foram obtidos 12039 registros de ingresso que, filtrados por nome, formaram um banco de dados com 5742 indivíduos. Registros de Matrículas de Servidores. Fundo 3.8, códices 3.8/1 (Polícia 1) a 3.8/22 (Polícia 22). Arquivo Histórico de Porto Alegre Moysés Vellinho (AHPA). Nas referências subsequentes: Matrícula, numeração do códice, AHPA.

14 Matrícula, 3.8/4. AHPA (grifo meu). Foram mantidos somente os prenomes dos policiais. As citações das fontes preservam a grafia dos originais.

15 Respectivamente Matrícula, 3.8/1 e 3.8/7. AHPA. 
subintendentes o regulamento de 1896 exigia alguma forma de comunicado ou relatório escrito. Excetuando-se as "partes" dos inspetores, os documentos remanescentes dos distritos da Polícia Administrativa, registros de ocorrências e correspondências, bem como os livros de Matrícula, geralmente eram assinados pelos subintendentes e inspetores e mantidos por esses ou amanuenses, que se reportavam a comunicados provavelmente verbais de agentes.

O concurso para inspetores e amanuenses instituído a partir de 1814 incluía as seguintes matérias: "1. Ortografia e caligrafia; 2. Aritmética (as quatro operações); 3. Redação de partes e ofícios; 4. Datilografia, das quais prestará provas perante o subintendente". O novo regulamento estabeleceu, obedecendo a cláusula de um convênio então instaurado com o governo do estado, o cargo de instrutor na Polícia Administrativa, cuja função era fazer com que auxiliares, inspetores e agentes cumprissem o regulamento. Para isso seriam realizadas reuniões semanais nos postos para ler os deveres e obrigações dos policiais. ${ }^{16} \mathrm{Na}$ documentação pesquisada não foram encontradas informações sobre esses instrutores e suas funções.

A despeito do caráter esparso das informações contidas nas fontes, pode-se presumir que ao longo da Primeira República saber ler e escrever, e posteriormente um mínimo de educação formal, era necessário para aqueles que encaravam a polícia como uma atividade mais estável, garantindo salário um pouco mais alto. Por outro lado, a Polícia Administrativa parece ter funcionado como porta de entrada para outras funções no serviço público municipal ou estadual, já que nas fichas da Matrícula constam muitos desligamentos e demissões "para servir" na Diretoria de Fazenda e de Higiene, na Viação Férrea, na Diretoria Geral, no Gabinete de Identificação e outros. Tais funções provavelmente só se abriam aos alfabetizados.

A maioria dos policiais ingressou com sua moralidade e boa conduta atestadas por um cidadão idôneo cujo nome era anotado na

16 Acto n. 115, de 31 de outubro de 1914. Leis, Decretos, Actos e Resoluções do Municipio de Porto Alegre. Período de março de 1909 a dezembro de 1916. Porto Alegre: Officinas Graphicas d'A Federação, 1930. AHPA. 
Matrícula. ${ }^{17}$ Constam na lista uma série de nomes de pessoas do Partido Republicano Riograndense (PRR) diretamente ligadas à administração estadual e municipal da época, como Borges de Medeiros (Presidente do Estado por 25 anos) e José Montaury (Intendente - prefeito - da capital do estado por 27 anos), entre outros. Não foi possível localizar na documentação os próprios atestados, mas foram encontradas certidões de assentamentos do Exército e da Guarda Nacional de seis policiais que bem poderiam ter cumprido essa função, na medida em que na Matrícula aparecem referências a "baixas" de instituições militares anotadas no campo do atestado. ${ }^{18}$ É possível também que muitos policiais tenham ingressado por meio de indicação verbal de pessoas de prestígio das quais só era anotado o nome, o que fica evidente quando a fonte menciona "ordem verbal do Dr. Intendente" no campo do atestado. Os atestados de boa conduta eram geralmente fornecidos por pessoas externas à Polícia Administrativa e que não parecem ter se responsabilizado pela conduta do indicado.

Individualmente, a pessoa que mais teria fornecido atestados foi o Coronel Marcos, responsável por quase um quinto do total. ${ }^{19}$ Nenhum outro nome listado chegou perto desse número. Figura destacada do PRR em Porto Alegre e homem de confiança dos líderes Julio de Castilhos e Borges de Medeiros, Marcos havia sido professor e amanuense do Tribunal da Relação em Porto Alegre, e teria ganho notoriedade política a partir da participação na propaganda republicana. Com a proclamação da República, recebeu o posto de Tenente Coronel da Guarda Nacional e participou das lutas da Revolução Federalista. Nos anos seguintes, atuou como suporte do partido e de suas vitórias eleitorais na capital do estado até morrer, em 1921. Em 1924 um dos Centros Republicanos da capital do estado levava seu nome. Sobre ele foi dito que conhecia eleitor por eleitor e era extremamente fiel ao partido, tendo sido eleito para a Assembleia dos Representantes em três legislaturas seguidas (1909, 1913 e

17 Somente em um pouco menos de um quarto do total de 5742 fichas individuais de policiais a Matrícula não consta informação de nome ou instituição que forneceu atestado (24,52\% ou 1408 campos vazios ou preenchidos com expressões como "sim" ou "boa").

18 Certidões (1893-1897). Subintendências, código 3.1. AHPA.

191058 atestados. 
1917). ${ }^{20}$ Dos seis assentamentos militares acima mencionados, cinco são da Guarda Nacional do município de Porto Alegre, datados de outubro e novembro de 1896 e visados pelo Coronel Marcos, o que mostra o papel que ele pode ter desempenhado na arregimentação de homens para a Polícia Administrativa desde a sua criação.

Depois do Coronel Marcos, o outro prócer republicano que individualmente mais forneceu atestados de conduta para ingresso na Polícia Administrativa foi Aurélio Viríssimo de Bittencourt, secretário e amigo pessoal de Julio de Castilhos. Aurélio de Bittencourt, que na Matrícula aparece com os títulos de "Cel.”; "Ten. Cel." e "Dr.", iniciou a vida profissional como tipógrafo e jornalista em Porto Alegre e foi um dos fundadores da sociedade Parthenon Literario. Em 1868 ingressou no serviço público como amanuense, tendo chegado a Secretário da Presidência da Província e, na República, da Presidência do Estado, onde trabalhou com Julio de Castilhos e Borges de Medeiros. Durante a Primeira República, até sua morte em 1919, Aurélio foi possivelmente um dos homens mais próximos do centro do poder, embora atuasse com discrição. Sua intimidade com Julio de Castilhos fica explícita na correspondência entre ambos. Em telegramas quase diários quando Julio se encontrava fora da cidade, Aurélio o informava de questões políticas e de governo, dos conflitos por cargos e nomeações, dos "cacetes" que vinham procurá-lo para que intercedesse junto ao chefe do PRR, das óperas que tinham se apresentado em Porto Alegre e comentava ainda sobre o clima, a saúde dos filhos e da esposa de Castilhos. Nesses telegramas do período de 1896 a 1903, o Coronel Marcos era frequentemente citado como um dos que privava de convivência mais íntima com Julio, e seu papel nas eleições, junto com outros correligionários pertencentes à "cabala" (dentre eles o subintendente e delegado de polícia Francisco Louzada, o "Louzadinha"), era também neles mencionado. ${ }^{21}$

20 FRANCO, Sérgio da Costa. Porto Alegre: guia histórico. Porto Alegre: Ed. da Universidade/UFRGS, 1988. p. 35.

21 MOREIRA, P. R. S., PENNA, Rejane (orgs.). Política e Poder nos Primeiros Anos da República: a correspondência entre Júlio de Castilhos e seu secretário, Aurélio Viríssimo de Bittencourt. Porto Alegre: EDIPUCRS, 2009. Anais do AHRS/volume 19. p. 71. 
Também expressiva era a quantidade de atestados proveniente de oficiais do Exército, Guarda Nacional e Brigada Militar, principalmente Coronéis. Juntando-se todas as patentes com os outros documentos de instituições militares (baixas, assentamentos, folhas corridas), chega-se a quase 40 por cento do total. Mas se contarmos somente as fichas que possuem indicação de quem forneceu atestado (eliminando os sem informação), os militares (incluindo o Cel. Marcos) teriam fornecido quase metade, sendo o Coronel Marcos responsável por praticamente um quarto desses. A existência de diversas "baixas" de regimentos ou batalhões no lugar do atestado de conduta poderia indicar uma valorização da experiência militar no momento do recrutamento de policiais, ou ainda uma forma de colocação para ex-soldados combalidos. ${ }^{22}$ No entanto, o número de policiais com profissão anterior militar registrada é pequeno em relação ao peso dos militares no atestado de conduta. Ou seja, mais do que a experiência, o prestígio dos oficiais militares é o que parece ter sido mais valorizado. Por outro lado, pode-se considerar que ex-praças que já haviam tentado outra ocupação voltassem às instituições militares onde haviam servido para buscar um documento que atestasse sua idoneidade, talvez por ser esse o único documento que possuíssem.

Além dos políticos e militares, a grande maioria dos outros "cidadãos idôneos" que deram os atestados tinha o nome acompanhado por algum título ("Doutor", "Desembargador") ou indicador de posição social (por exemplo: "Walter Gerdau, negociante"; "Kappel \& Cia."; "comerciante"; "negociante a rua [...]", "estabelecido a rua [...]", etc.). Nesse sentido, a listagem de nomes e instituições que firmaram atestados pode ser vista como uma escala de posições, títulos e atributos que conferiam prestígio e distinção a alguns homens em relação a outros na Porto Alegre da época. Analisando os nomes e posições dos fornecedores dos atestados de conduta, uma das conclusões possíveis é que a arregimentação de

22 Tendo observado a migração de oficiais do exército para o Corpo Policial Permanente de São Paulo no século XIX, André Rosemberg levantou a possibilidade de a polícia oferecer a esses homens uma rotina mais suave de trabalho, servindo como espécie de "cabide de emprego". ROSEMBERG, op. cit. p. 156. Poderia dizer o mesmo para a polícia de Porto Alegre na Primeira República, com a diferença de que, neste caso, tratavam-se de soldados e não ofíciais. 
homens para a polícia poderia ter claras finalidades eleitorais e práticas para os governantes, na medida em que estabeleceria laços de fidelidade e compromissos mútuos ligando os governantes em posição mais destacada aos seus correligionários mais discretos e esses a trabalhadores comuns. Somente por meio dos dados da Matrícula não é possível saber se a principal moeda de troca nessa relação era o emprego na polícia ou o voto/consentimento e nem o sentido em que essa relação se dava (de cima para baixo ou de baixo para cima na pirâmide de poder). Provavelmente tanto a moeda quanto o sentido das trocas tenham se alternado de acordo com a conjuntura política e econômica ao longo da Primeira República. Se o emprego na Polícia Administrativa era vantajoso para alguns trabalhadores, eles ficariam em dívida com quem forneceu o atestado. Se, por outro lado, conseguir "voluntários" para a polícia nem sempre era fácil, quem ficava em posição de agradecimento era o correligionário que assumia a função de recrutador, como parece ser o caso do Coronel Marcos.

A exigência de atestados de moralidade e boa conduta era comum na Primeira República e no período imperial, ${ }^{23}$ de modo que é fácil interpretar tal prática como apadrinhamento no serviço público. No entanto, a natureza da relação entre quem fornecia e quem recebia tais documentos não fica clara, isto é, não se sabe quais eram os compromissos que se estabeleciam entre um e outro. $\mathrm{O}$ que parece certo é que o prestígio de quem assinava o atestado de conduta não era abalado pelo mau procedimento dos seus indicados no trabalho policial, pois não foi observada na análise quantitativa nenhuma ligação entre alguns "cidadãos idôneos" em especial - como o Coronel Marcos e Aurélio de Bittencourt - e as punições disciplinares recebidas (ou não) por seus indicados. Possivelmente, com o crescimento da população da cidade, a concessão desses atestados, que já era procedimento usual, tenha se transformado em algo corriqueiro para cidadãos de prestígio, e estes não conseguiam manter controle sobre a moralidade e boa conduta da maioria dos indicados.

23 Ver ROSEMBERG, op. cit. e SILVA, Wellington Barbosa da. Entre a liturgia e o salário: a formação dos aparatos policiais no Recife do século XIX (1830-1850). Tese (Doutorado), PPG em História, Universidade Federal de Pernambuco, Recife, 2003. 
Relações clientelistas operavam dentro da polícia de variadas formas. O subintendente do $1^{\circ}$ Distrito Francisco Louzada intercedeu em 1897 pela nomeação de um agente cuja família, que vivia em estado de miserabilidade, era "protegida" do seu pai. Em 1904 Louzada foi acusado de "proteger cegamente" um dos inspetores do distrito, privilegiando-o na distribuição dos turnos de trabalho. No mesmo documento, porém, o inspetor que denuncia o favorecimento recebido pelo colega, chamando-o de "adulão", subira numa cadeira para discursar em nome de um deputado. ${ }^{24}$ Dado o bipartidarismo existente no Rio Grande do Sul da Primeira República, o alinhamento com as correntes políticas era fundamental para aqueles que almejavam trocar fidelidade por alguma forma de participação nas instituições estatais. Além disso, ficar sob a proteção de alguém superior na hierarquia social podia significar para os mais pobres ajuda material e, para todos, simbólica. ${ }^{25}$

Atestados de conduta eram documentos importantes precisamente para os trabalhadores desprovidos de padrinho ou protetor e que tinham de comprovar idoneidade antes da era da difusão da identificação criminal e civil. Somente a partir de 1912, com a expansão dos serviços do Gabinete de Identificação e Estatística e o aperfeiçoamento do cadastro dos delinquentes, gradualmente passou a ser possível às próprias polícias Judiciária e Administrativa fornecer atestados de conduta à população de Porto Alegre. No entanto, para o preenchimento dos seus quadros a prática antiga continuou em vigor pelo menos até a extinção da polícia municipal em 1929. Do fim do século XIX até essa data, portanto, os procedimentos de engajamento não parecem ter se tornado mais restritivos, exceto pelo já mencionado concurso para inspetores a partir de 1914, e que não atingia os escalões inferiores que formavam a maioria dos policiais, os agentes.

Provenientes das classes trabalhadoras urbanas e rurais, trabalhadores sem qualificação em sua grande maioria, os homens engajados ficavam em média pouco tempo no serviço de

24 Inquérito Administrativo, 14/06/1904. Fundo 3.3: Subintendências, Caixa 1. AHPA.

25 CASTEL, Robert. As metamorfoses da questão social: uma crônica do salário. 8. ed. Petrópolis: Vozes, 2009. 128-129. 
policiamento. Grande número entrava e saía no intervalo de poucos meses ou apenas alguns dias, e as médias de permanência no serviço oscilavam em torno dos quatro anos. Mesmo aqueles com tempo maior dificilmente ficavam por um período contínuo, experimentando interrupções ocasionadas por saídas voluntárias ou expulsões disciplinares e reingressando após algum tempo, o que dificulta as generalizações sobre a configuração da "carreira" policial nesse contexto. Tais dados se assemelham aos encontrados em pesquisas semelhantes em corpos policiais do século XIX no Brasil e outros países, e indicam não só as dificuldades que novas polícias tem para formar um corpo de funcionários disciplinado e estável, como a relação entre o processo de profissionalização da atividade e a estabilização do pessoal. ${ }^{26}$

Enquanto os motivos que levavam trabalhadores pobres a se engajarem na polícia ainda estão abertos para discussão, as razões dos policiais deixarem o serviço são mencionadas nas fontes. Mesmo que o motivo da saída da Polícia Administrativa apareça em menos da metade das fichas de policiais (2436 homens, 42\% do banco de dados), sabe-se que desses a grande maioria saiu a priori involuntariamente, ou seja, foi desligada, exonerada ou expulsa. Mas como mostra a Tabela 1 , o número dos que saíram voluntariamente ("a pedido") também era expressivo. Muitos homens deixavam a Polícia Administrativa para assumir trabalho em outra repartição pública estadual ou municipal, como mencionado acima, e constam no registro ou como transferidos, ou simplesmente desligados. O exmarítimo Idalino estava há oito anos na polícia quando foi "desligado por ter passado a empregado público da Intendência Municipal”; André Francisco, antes empregado no comércio, foi "demitido, passando a auxiliar de gabinete da Chefatura de Polícia"; e o estudante de 21 anos Mario ficou poucos meses na Polícia

26 SHPAYER-MAKOV, Haia. The making of a police labour force. Journal of Social History. n. 24, p. 109-134, 1994. SHPAYER-MAKOV, Haia. The Making of a Policeman: A Social History of a Labour Force in Metropolitan London, 1829-1914. Aldershot and Burlington: Ashgate, 2002. p. 67. GAYOL, Sandra. Entre lo deseable y lo posible. Perfil de la policía de Buenos Aires en la segunda mitad del siglo XIX. Estudios Sociales. Santa Fe, Año VI, n. 10, p. 123-138, 1996. EMSLEY, 1996, op. cit. ROSEMBERG, op. cit. 
Administrativa e "foi exonerado por ter sido nomeado quarto escriturário da Intendência". ${ }^{27}$

Tabela 1: Policiais da Polícia Administrativa de Porto Alegre por Motivo de Saída, 1896 a 1929

\begin{tabular}{|c|c|c|}
\hline Motivo de saída & Totais & Percentuais \\
\hline $\begin{array}{l}\text { Desligado, exonerado ou expulso sem especificação de } \\
\text { motivo }\end{array}$ & 1631 & 66,95 \\
\hline Exoneração a pedido & 400 & 16,42 \\
\hline $\begin{array}{l}\text { Desligado, exonerado ou expulso por infração disciplinar } \\
\text { ou delito }\end{array}$ & 231 & 9,49 \\
\hline Falecimento & 127 & 5,21 \\
\hline Extinção do cargo & 17 & 0,7 \\
\hline Aposentadoria & 26 & 1,06 \\
\hline $\begin{array}{l}\text { Desligado para servir em outra repartição pública ou } \\
\text { Exército }\end{array}$ & 4 & 0,16 \\
\hline Total * & 2436 & 100 \\
\hline \multicolumn{3}{|c|}{$\begin{array}{l}\text { * Foram contados como motivos de saída apenas os últimos registros de cada } \\
\text { indivíduo que diziam respeito à demissão e desligamento (voluntários ou não), } \\
\text { expulsão, falecimento e aposentadoria, deixando de lado aqueles cujo último } \\
\text { registro mencionava promoção, transferência, licença de saúde, etc. } \\
\text { Fonte: Registros de Matrículas de Servidores. Fundo } 3.8 \text {, códices } 3.8 / 1 \text { a 3.8/22. } \\
\text { AHPA. }\end{array}$} \\
\hline
\end{tabular}

Ainda que a quantificação dos motivos de saída ajude, e muito, a delinear um quadro do movimento de pessoal na instituição, alguns aspectos desse processo não podem ser deduzidos imediatamente dos números. Por exemplo, os dados da Tabela 1

27 Matrícula, 3.8/14 e 3.8/17. AHPA. Os termos "demitido", "desligado" e "exonerado" nem sempre significam que o sujeito deixou a polícia involuntariamente, já que também eram usados nos casos em que eles saíam para tomar outro emprego. 
mostram que as infrações disciplinares não figuravam como principal motivo de saída. Entretanto, a análise das "observações" anotadas nas fichas individuais da Matrícula evidencia que grande parte dos expulsos, desligados e exonerados sem especificação de motivo sofreram punições disciplinares em abundância que foram anotadas em suas fichas. Dentre os policiais cujos registros especificaram as infrações ao regulamento - ou mesmo ao Código Penal - cometidas, percebe-se que as mais frequentes eram o abandono do serviço, as ligadas ao consumo excessivo de álcool e/ou presença em tabernas (normalmente associadas, mas nem sempre explicitadas na fonte) e o cometimento de atos classificados como desordens ou imoralidades. Enquanto algumas fichas continham somente o artigo do regulamento infringido, em outras o motivo para expulsão era descrito com mais detalhe: "por ter arribado do quadro e ter ido dormir na latrina do posto"; "por ter sido encontrado dormindo na Praça da Harmonia e ser dado ao vício da embriaguez"; "por entrar numa bodega fardado"; "por ser ébrio"; "por incompetência para o serviço"; "por ter falsificado o atestado"; "por excesso de licenças"; "por demonstrar falta de caráter"; "por ter sido encontrado jogando osso com diversos vagabundos e desordeiros"; "por ter sido encontrado jogando e morar em casa de meretriz"; "por ter espancado um preto velho"; "por ter ferido sua mulher"; "por quebrar os vidros da janela de sua amásia". Essa lista ilustra como se sobrepunham avaliações sobre o que os policiais faziam, o que supostamente eram (ébrio ou sem caráter) ou como viviam, bem como as expectativas sobre como deveriam ser e se comportar.

Coerente com a idealização do "bom policial", o regulamento de 1896 exigia comportamento exemplar dos homens engajados, e era rigoroso nas punições:

Art. 89 - O agente deve evitar qualquer acto indecoroso que faça diminuir ou perder a estima de seus superiores em particular e do publico em geral; deve, por conseguinte, abster-se do jogo, da bebida, da convivência com pessoas de má conducta e de qualquer excesso, para que ninguem possa censurar-lhe algum acto indigno, nem, por ter conhecimento d'este deixe de tel-o na 
consideração necessaria. Tambem não deverá participar dos divertimentos durante o seu serviço; mesmo estando de folga, deverá abster-se de diversões de seriedade duvidosa. Como sejam bailes publicos, mascarados ou não.(...)

Art. 96 - Jamais terá altercações com qualquer pessoa e, si for tratado de modo inconveniente, admoestará com boas maneiras a quem o tiver maltratado, para que se modere, detendo-o sómente quando a admoestação tenha sido inefficaz. (...)

Art. 109 - Deverá apresentar-se em publico com asseio no corpo e limpeza no vestuario, sempre penteiado, de cabellos cortados, collarinhos limpos e uniforme sem manchas, rasgões nem remendos, afim de inspirar sympathia e respeito aos cidadãos.(...)

Art. 113 - É prohibido aos agentes policiaes que estiverem em serviço entrarem em cafés e quaesquer casas de bebidas alcoholicas, salvo no exercicio de suas funcções ou sendo chamados para prestar seus serviços. Mesmo não estando em serviço, não poderão entrar uniformisados e com seus distinctivos n'aquellas casas. ${ }^{28}$

Como é possível observar nos artigos acima, o regulamento da Polícia Administrativa tinha a pretensão de disciplinar o comportamento dos policiais tanto em serviço como nas horas de folga e as dificuldades de adaptação dos agentes a tais exigências explicam porque quase todas as fichas de pessoal completas tinham registro de punições. Como essas frequentemente implicavam em corte ou perda da gratificação que compunha os vencimentos, possivelmente atuavam mais como desestímulo à permanência dos policiais do que como estímulo ao bom comportamento desejado pelos superiores. As punições iam da advertência verbal pelo superior imediato à expulsão, passando por suspensões e prisões sem vencimentos por prazos variáveis, as quais muitas vezes antecediam a demissão. Formalmente, a reincidência na infração agravava a pena.

28 Acto n. 20, de 10 de outubro de 1896. Leis, Decretos, Actos e Resoluções do Municipio de Porto Alegre. Período de maio de 1897 a dezembro de 1908. Porto Alegre: Officinas Graphicas d'A Federação, 1930. AHPA. 
No entanto, as fontes mostram que a distribuição das punições nem sempre seguia o prescrito no regulamento, pois as mesmas infrações eram punidas ora com mais, ora com menos rigor. Na mesma linha, alguns agentes eram expulsos por infrações que, para outros, não impediam a permanência por períodos mais longos, assim como a "ficha suja" raramente obstaculizava o reingresso e mesmo as promoções. $^{29}$

As regras e critérios não escritos que regiam o cotidiano da polícia (como organização hierárquica) e do policiamento aparecem nos inquéritos administrativos abertos para apurar algum desvio de conduta ou denúncia contra policiais. Nessas fontes, muitas vezes os policiais se viam obrigados a explicar suas ações, de forma que a análise de alguns casos ajuda a iluminar relações que não se explicitam nas fontes seriadas.

O policial Lothario ingressou na Polícia Administrativa em janeiro de 1901 com 29 anos, solteiro, profissão anterior agência, natural do Rio Grande Sul, apresentando atestado de conduta fornecido pelo Coronel Marcos. Sua última anotação na matrícula é a da exclusão em setembro de 1909. Nesse período de quase nove anos em que permaneceu na polícia, Lothario figurou em três inquéritos administrativos, sempre qualificado como inspetor do $1^{\circ}$. Distrito, localizado na área central da cidade e comandado de 1896 até 1925 pelo ex-Tenente Coronel da Guarda Nacional Francisco Louzada. No primeiro inquérito, de junho de 1904, Lothario foi acusado de ter abandonado a seção onde se achava em serviço e, em companhia de outros três inspetores e um agente (apenas um dos inspetores estava de folga), todos fardados, ter-se juntado numa casa de pasto na Travessa 2 de Fevereiro ao negociante de secos e molhados Propicio, que, em comemoração ao seu aniversário, havia encomendado uma galinha ao molho pardo e convidara os policiais. A ceia, regada a uma garrafa de vinho verde, duas de Cerveja Ritter de Pelotas, duas de cerveja Bopp e duas de água Seltz, finalizada com café sem açúcar, acabou em discussão e troca de ofensas entre os inspetores. Segundo alguns, a culpa fora de dois que haviam exageraram na bebida e século XIX. ROSEMBERG, op cit, p. 149. 
perdido a compostura; para outros o inspetor Jacintho teria exagerado no cumprimento do dever ao repreender os colegas pela algazarra e, por fim, dar-lhes voz de prisão. O proprietário do restaurante declarou que as bebidas que serviu "não dava para imbriagar (sic) ninguém", mas os inspetores Moysés e Carvalho, que chegaram junto com o aniversariante, "já teriam bebido em outra parte, pois que um delles vomitou bastante logo que chegaram". Nesse inquérito, Lothario é quem menos aparece, visto as acusações terem se polarizado entre Jacintho e os inspetores Moysés e Carvalho, mas ele foi como os outros punido com 30 dias de suspensão sem vencimentos. ${ }^{30}$

Os outros dois inquéritos instaurados contra Lothario foram os seguintes: em julho de 1908 uma mulher chamada Candida (também referida como a meretriz Lola de tal) prestou queixa no $1^{\circ}$. Posto por ter sido por ele assediada, perseguida e ameaçada; e em julho de 1909 o subintendente Louzada resolveu averiguar seu mau procedimento como frequentador contumaz de casas de tavolagem. Em ambos, todos os depoimentos transcritos o acusam de infrações disciplinares em série: faltas não justificadas e abandono do serviço, frequentar meretrizes, bares e casas de jogo em serviço e fardado, embriaguez e desordem.

No inquérito de 1908, Lothario apresenta defesa, provavelmente escrita por algum advogado que teve acesso aos "autos", onde faz uso não só de estratégias e jargões jurídicos, como também de argumentos de autoridades como o criminologista italiano Cesare Lombroso. Habilmente, diz ter sido demovido de seu intento inicial de apresentar testemunhas da sua versão dos fatos porque não seria necessário, já que a prova testemunhal era "fundamentalmente suspeita" por provir de meretrizes. Além disso, explora lacunas e lança dúvidas sobre os depoimentos dos colegas policiais que teriam atendido a ocorrência, tomando o cuidado de não desqualificá-los. Seu objetivo principal é desqualificar a queixa por meio da desqualificação da queixosa e das duas vizinhas que Candida apresentou como testemunhas: 
Liga-as [as 3 mulheres] a inquebrantavel solidariedade dos desclassificados, une-as o mesmo mister que se desenvolve a des'horas; reune-as o mesmo viveiro suspeito que é o becco Itaperú...

(...) Entre as testemunhas suspeitas, todos os juristas incluem, juntamente com os malfeitores, os vadios, os jogadores - as meretrizes. (...)

Lombroso e Ferrero (sic), no seu profundo livro sobre a Mulher criminosa, a prostituta e a mulher normal dizem que as prostitutas, como os criminosos, mostram uma tendência invencivel para a mentira, mesmo sem rasão (sic). 31

$\mathrm{Na}$ conclusão, o acusado admitiu ter sido sua única falta entrar fardado nos restaurantes D. Quixote e Vencedor. Declarou-se chefe de família morigerado e cumpridor dos deveres, seguro de que as calúnias de três mulheres públicas "não lhe vão deshonrar a farda que sempre honrou" e pediu "Justiça". A comissão de inquérito concluiu que Lothario transgrediu o regulamento em três parágrafos de dois artigos e o subintendente Louzada recomendou sua demissão a bem do serviço, mas infelizmente no documento não consta despacho do Intendente, a quem cabia a aplicação da penalidade. $\mathrm{Na}$ Matrícula não há registro de punição a Lothario em 1908. Lá consta uma transferência em 1902, uma suspensão por ter abandonado o serviço e ser depois encontrado dormindo no posto, outras suspensões em 1906 por ter abandonado a sua seção para ir a uma "casa de má fama" e por ser encontrado em uma "bodega" e, por fim, um rebaixamento de inspetor a agente em 27/07/1909 por ter sido encontrado em casa de tavolagem. ${ }^{32}$ Ou seja, mesmo sem ter convencido a comissão de inquérito, é possível que a defesa tenha funcionado, pois em 1909, um ano depois da queixa de Candida, novamente Lothario foi alvo de outro inquérito administrativo, dessa vez conduzido diretamente por Louzada. Este subintendente recolheu

31 Provavelmente o "Ferrero" mencionado na fonte seja Enrico Ferri. Inquérito Administrativo, 09/07/1908. Fundo 3.3: Subintendências, Caixa 1. AHPA (sublinhados à tinta no original).

32 Respectivamente: Matrícula, 3.8/1, 3.8/5 e 3.8/12. AHPA. 
na ocasião vários depoimentos, mais uma declaração da senhoria para quem o acusado devia aluguel, sobre o que qualificou de "majestoso modo de vida do Insp. Lottario" e foi ainda pessoalmente verificar sua entrada em uma casa de jogo, quando não aparecia há 42 dias para trabalhar alegando doença. Louzada concluiu o inquérito recomendando a "demissão a bem da disciplina e moral da Polícia Administrativa, ou rebaixamento definitivo do posto de Inspector da Policia" (grifo meu). O Intendente resolveu pelo rebaixamento e posteriormente demissão caso ele continuasse o mau procedimento. ${ }^{33}$

A aplicação de punições era claramente discricionária. Lothario aparentemente só foi excluído em setembro de 1909 - não foram encontrados registros posteriores e essa data - enquanto muitos outros foram sumariamente expulsos por serem encontrados em serviço dormindo, fumando, sentados em bancos de praça, encostados em batentes de portas, paredes ou postes. As discrepâncias nos critérios de aplicação de punições passam certamente pelas relações sociais e de poder que alguns desses homens que trabalhavam no policiamento de Porto Alegre na Primeira República entretinham com seus chefes, colegas, compadres, padrinhos ou protetores de condição social superior ou inferior às suas, e que podiam ser acionadas em momentos de dificuldade, cuja eficácia provavelmente era maior que a aplicação das regras escritas.

Conforme o regulamento, nenhum servidor poderia ser demitido sem um inquérito para apuração de suas faltas. Mas acredito que os inquéritos só tenham sido abertos quando uma das partes manifestava interesse em defender ou a reputação pessoal ou a da polícia, e quando denúncias chegavam ao Intendente por meio de queixas formais ou notícias de jornais. Foram encontrados 57 inquéritos envolvendo policiais municipais entre 1897 e 1928, nem todos completos (possivelmente tenham se perdido algumas partes), vários arquivados por falta de provas, e dos concluídos (que possuem despacho final do Intendente) em apenas sete os inspetores e/ou agentes acusados foram demitidos, tendo nos demais sido punidos com suspensões, rebaixamentos ou transferências de distrito. Já nos registros de pessoal, a quantidade de policiais excluídos e reincluídos 
"por ordem verbal do Snr. Dr. Intendente" é muito grande, o mesmo no que se refere ao percentual das entradas e saídas em cada ano. Em uma polícia cujo efetivo variou entre 234 (1898) e 556 (1925) homens ao longo dos seus 32 anos de existência, as proporções de excluídos ou demitidos por ano ia de 20 a 45 por cento, acompanhada de taxas de inclusões e reinclusões de 23 a 60 por cento, o que evidencia grande rotatividade e, consequentemente, instabilidade dos quadros. ${ }^{34}$

No inquérito aberto para apurar o conflito entre inspetores iniciado na ceia de aniversário do negociante Propicio, em junho de 1904, os inspetores Moysés e Carvalho sentiram-se prejudicados por terem sido demitidos no dia seguinte, enquanto os outros três policiais comensais foram punidos com três dias de prisão (que não teriam cumprido). Em protesto, eles enviaram duas cartas ao intendente José Montaury: a primeira reclamava da desigualdade nas punições, colocava sua versão dos fatos e solicitava abertura de inquérito; três dias depois a segunda denunciava que o inquérito estaria sendo conduzido de forma ilícita. Nela acusavam o inspetor Jacintho, o mesmo que lhes deu voz de prisão e que redigiu a "Parte" que ensejou a demissão, de ter ele mesmo, em companhia do amanuense inspetor Olegario, que era seu compadre, interrogado sobre o caso os três agentes e distorcido as declarações de dois que eram analfabetos, para quem sequer teria sido lido o que fora escrito "a seu rogo". Além disso, escreveram que "o sub Intendente do $1^{\circ}$. Dist ${ }^{\circ}$. protege cegamente ao Inspector Jacintho", dando-lhe regalias na distribuição dos turnos de trabalho, "assim é que o Sub Intendente fará tudo em favor daquelles infractores para que não fique desmoralizada sua parte, e assim possa ainda proteger seu affeiçoado Jacintho (...)". Moysés e Carvalho se mostraram indignados por terem sido tratados como bêbados e desordeiros ao serem presos por Jacintho na noite do aniversário, e se propuseram a apresentar atestados de terceiros confirmando que: não tinham o "triste e repugnante vício da embriaguez" pois que "ufanamo-nos em pertencer a familias conhecidissimas n'esta Capital, aonde rezidem a longos anos".

34 A população de Porto Alegre na época cresceu de 73674 habitantes em 1900 para um pouco mais de 234 mil em 1928, e o número de policiais variava a cada ano e era definido no orçamento municipal, mas oscilou entre 234 e 556, o que significava 1 para 303 habitantes em 1900 e 1 para 574 habitantes no último ano de funcionamento desta polícia, 1928. MAUCH, op. cit. 
Pediam a chance de se reabilitar "não só entre ex-collegas companheiros e o Publico em Geral, apezar de que não desejamos continuar a servir". Segundo depoimento de um agente que também participara da ceia, depois que todos haviam comido o inspetor Carvalho "subio em uma cadeira e dispunha-se a discursar, disendo representar o deputado Alfredo Varella", no que foi repreendido por Jacintho, o qual então foi chamado de "adulão e engrossador". A seguir, atraído pelo barulho que Carvalho fazia batendo com a faca nas garrafas e pedindo palitos, chegou o dono da casa de pasto, e teria se desenrolado o seguinte diálogo: "Se fosse uma reunião de paisanos, os senhores haviam de reagir, prendendo-os em continente (sic), mas é os senhores da polícia, quem é que reage?" 35

É raro encontrar nas fontes institucionais descrição clara da proteção de alguns funcionários em detrimento de outros. Contudo, não há porque duvidar do peso das práticas de apadrinhamento e o compadrio dentro da polícia municipal, não só no processo de ingresso - onde os atestados de conduta o tornam mais claro - mas também influenciando diretamente nas possibilidades de construção senão de uma "carreira", pelo menos de uma posição mais favorável dentro da instituição. Isso significa que, embora escritos e especificados, os critérios efetivamente aplicados na distribuição de punições e promoções, assim como no ingresso e exclusão, envolviam relações pessoais, compromissos políticos, classificações morais, em suma, relações de poder que passavam ao largo das regras escritas, mas que provavelmente eram do conhecimento senão de todos, daqueles que ficavam mais tempo na polícia.

Considerando o volume de reincidências nas infrações mais comuns, como ser pego dormindo ou fumando em serviço, conversando com meretrizes ou entrando em bodegas, supõe-se que a imposição de disciplina sobre o corpo de policiais era restrita. Cabia aos inspetores a vigilância sobre os procedimentos dos agentes do seu setor e dos outros inspetores, o que implica que só seriam registradas as infrações que eles quisessem ou fossem obrigados a reportar por sua gravidade, pela presença de testemunhas ou por denúncias. Nesse 
sentido, a possível existência de camaradagem ou "espírito de corpo" entre os policiais contribuiria para o encobrimento do comportamento irregular no trabalho, e tais relações tendem a deixar menos rastros na documentação do que os conflitos. $\mathrm{O}$ inspetor Christovão foi suspenso por oito dias em maio de 1906 por ter tido conhecimento de que agentes haviam participado de uma jogatina e não ter cumprido seu dever de comunicar o fato a autoridade superior. ${ }^{36}$

Cabia ao Intendente Municipal a decisão final sobre aplicar, ou não, as punições aos policiais. Nos inquéritos administrativos analisados foram poucos os casos de demissão. Mas outros detalhes importantes sobre tais inquéritos devem ser considerados: havia casos em que a comissão de inquérito, normalmente formada por Subintendentes, recomendava punições mais severas do que as que o Intendente acabava por definir no seu despacho final; e há casos em que mesmo essas punições parecem não ter sido aplicadas. Em novembro de 1924, por exemplo, em depoimento no inquérito administrativo sobre as arbitrariedades supostamente praticadas por um inspetor, o Capitão Subintendente do $4^{\circ}$ Distrito e chefe imediato do acusado, declarou o seguinte:

Que na administração passada o Inspector João (...), portou-se mal, isso por mais de uma vez, pelo que costumava tomar as providencias regulamentares, dando sciencia ao doutor ex-intendente; que apezar disso parece-lhe que os castigos aplicados a esse Inspector eram muito brandos, porquanto elle nunca se corrigia e as faltas se sucediam a miudo; que pode afirmar tambem que esse Inspector, dava-se ao vicio da embriaguez e que apezar dos conselhos e admoestações severas, no intuito de faze-lo emmendar-se, ainda assim elle continuava praticando aquelle vicio $(. ..){ }^{37}$

36 MATRÍCULA, códice 3.8/12. AHPA.

37 O "doutor ex-intendente" era José Montaury que, depois de sete vezes reconduzido ao cargo desde 1897, havia sido substituído por Octavio Rocha no mês anterior ao depoimento. Inquéritos Administrativos, 27/10/1924. Fundo 3.3: Subintendências, Caixa 2. AHPA (grifo meu). 
A documentação é pródiga em conflitos entre policiais, muitos dos quais gerados das punições aplicadas de uns sobre os outros, como no caso anteriormente descrito da ceia de aniversário do negociante Propicio. Não tivesse o inspetor Jacintho resolvido acabar com a algazarra na casa de pasto, dar voz de prisão aos colegas e no dia seguinte escrever a "Parte" sobre o ocorrido, nada se saberia. Não tivessem os inspetores presos e demitidos querido resguardar sua reputação e reclamado abertura de inquérito administrativo, só teria restado (talvez) a "Parte" dada por Jacintho, que traz poucos detalhes sobre uma história que, como tantas outras na documentação judicial e policial, começou com camaradagem entre homens e acabou em conflito. Entre 57 inquéritos administrativos analisados, no mínimo 14 tratam de desavenças entre policiais, as quais ocasionalmente apareceram na documentação da Polícia Judiciária. Em 1898 o agente paraense José Maria atacou um inspetor porque este lhe havia aplicado penas disciplinares, dizendo em voz alta enquanto desembainhava o sabre "que este não mais havia de dar parte de ninguém". Já preso, declarou que sofria perseguição de alguns funcionários do posto policial. ${ }^{38}$ José tinha 28 anos e estava há menos de seis meses na polícia, onde ingressara com baixa do Exército, enquanto o inspetor, o alagoano Manoel, ex-barbeiro com 32 anos, era um dos que havia entrado logo que a instituição foi criada, em novembro de $1896 .{ }^{39}$ Conflitos entre colegas e com superiores são tão previsíveis dentro de instituições policiais quanto a existência de proteção mútua e acobertamento de infrações. Conforme Clive Emsley, é difícil conceber algum ambiente de trabalho onde animosidades pessoais e relações de poder não tenham papel tão significativo quanto as amizades e solidariedades, e nesse aspecto as polícias não diferem de outros trabalhos. ${ }^{40}$

$\mathrm{O}$ alto número de servidores que entrava e saía por ano, aliado à predominância de tempos de serviço descontínuos e curtos, dificultava o processo de formação do perfil de policial desejado. As

38 Livro no. 7, Registro de Autos. $2^{\mathrm{a}}$ circunscrição. Fundo Polícia, Códice 7. Arquivo Histórico do Rio Grande do Sul.

39 Registros de Matrículas de Servidores. Fundo 3.8, códices 3.8/3 e 3.8/22. AHPA.

40 EMSLEY, Clive. The policeman as worker: a comparative survey c. 1800-1940. International Review of Social History. n. 45, p. 89-110, 2000. p. 106. 
práticas de recrutamento e desligamento observadas nas fontes indicam procedimentos clientelistas e aplicação discricionária das punições. Ao recontratarem homens antes expulsos por indisciplina, os próprios recrutadores - provavelmente subintendentes enfraqueciam as possibilidades de contarem com um corpo de "bons policiais". Por que o regulamento seria o principal guia para os policiais nas ruas, se sua aplicação dentro da corporação era eivada de contradições? Por outro lado, em troca da submissão a um regulamento muito exigente e um trabalho desprestigiado, os salários equivaliam ao de um trabalhador não especializado. Os governantes tinham plena consciência do vínculo entre a questão salarial e a formação do bom policial. Já na época da reorganização das polícias no estado, o então Presidente Julio de Castilhos escreveu na exposição de motivos que introduziu o projeto de lei o seguinte: "Efetivamente, as funções policiais exigem competência especial adquirida por uma verdadeira habilitação profissional; mas, como despertar vocações, conseguir agentes aptos, sem o estímulo de vantagens pecuniárias que os coloquem ao abrigo das necessidades da vida?". Como outros funcionários municipais e estaduais, os policiais passaram a fazer jus a licenças e aposentadoria quando ficassem inválidos em serviço, o que certamente representava uma grande vantagem em relação à vala comum dos trabalhadores pobres. Ao longo do tempo, ampliaram-se os incentivos salariais e de carreira. A partir de 1919 foi instituída uma gratificação de dez por cento sobre os vencimentos para aqueles que contassem com mais de sete anos de serviço efetivo, e no ano seguinte os policiais passaram a receber por horas extras que excedessem a jornada de nove horas. Mas a instabilidade no quadro de pessoal indica que tais incentivos não conseguiam reter a maioria dos ingressantes.

As práticas analisadas nesse artigo provavelmente representam a adaptação dos chefes da polícia municipal às contingências: orçamento reduzido, baixos salários, pouca disponibilidade de mão-de-obra, aparelhamento político dos cargos

41 Exposição de motivos da decretação das leis. Relativo à Lei de reorganização policial do Rio Grande do Sul. In: Leis, decretos e actos do Governo do estado do Rio Grande do Sul. 1896. Porto Alegre: Officinas Graphicas d'A Federação, 1926. L0627. Arquivo Histórico do Rio Grande do Sul. Essa Exposição de motivos foi assinada por Julio de Castilhos em 20/08/1895. 
mais altos. Mais que tudo, representam que o policiamento administrativo nos moldes idealizados nas leis e regulamentos - a prevenção dos delitos, o patrulhamento cotidiano das ruas, a imposição da ordem e moralidade, a segurança pública, enfim - não era uma prioridade para os governos estadual e municipal ao longo da Primeira República. Propalado nos discursos oficiais como imprescindível para alcançar a ordem e moralidade civilizada, o policiamento mostrou-se tarefa complexa e dispendiosa, legada a homens mal pagos e sem treinamento específico, ${ }^{42}$ constantemente criticados pela brutalidade. Os policiais podiam permanecer sem treinamento porque, afinal, a imposição da ordem no espaço público continuou sendo encarada como atividade não especializada dirigida aos mais pobres, e o poder de polícia imposto mais pela força que pela lei.

RECEBIDO EM: 15/05/2016 APROVADO EM: 20/06/2016

42 "As instituições de treinamento formal são, de um modo geral, muito recentes, e provavelmente os dados existentes são escassos. O treinamento de agentes policiais no séc. XIX e no início deste século $[\mathrm{XX}]$ era em grande medida uma questão de experiência diária e da maneira como essa experiência era compartilhada." BRETAS, 1997, op. cit. p. 15-16. 